\title{
A BRINQUEDOTECA ESCOLAR COMO AUXILIAR NA SUPERAÇÃO DE CONFLITOS DA INFÂNCIA: AGRESSIVIDADE E INDISCIPLINA
}

\author{
Eliane Fonseca Carrara, Helen Cristina Gaia Rocha.Universidade Estadual Paulista "Júlio Mesquita Filho" - \\ Faculdade de Ciências e Tecnologia - UNESP, Licenciatura em Pedagogia, Campus de Presidente Prudente/ São Paulo. \\ E-mail: efonsecacarrara@gmail.com.
}

\begin{abstract}
RESUMO
O processo educacional tem se tornado cada dia mais complexo, pois as crianças já chegam nas escolas com muitos conflitos - os quais não conseguem resolver sozinhos. Por esta razão, é necessário um olhar atento e individual com cada criança. O objetivo deste estudo foi mostrar o quanto os encontros lúdicos na brinquedoteca escolar ajudam a criança a reestruturar sua própria história e a se desenvolver de forma significativa em diversos aspectos. A metodologia constou de uma pesquisa qualitativa cujo estudo de caso se fundamentou nos livros de Winnicott. Os resultados foram as observações - realizadas pela professora - acerca do desenvolvimento e avanços que Carlos obteve ao final dos encontros. Concluímos que a brinquedoteca escolar ajudou Carlos a enfrentar e resolver seus conflitos da infância por meio da brincadeira.
\end{abstract}

Palavras-Chave: brinquedoteca, agressividade, infância, conflitos e aprendizagem.

\section{THE SCHOOL HOUSEKEEPING AS AN AUXILIARY IN THE EXCESS OF CHILDHOOD CONFLICTS: AGGRESSIVENESS AND INDISCIPLINA}

\begin{abstract}
The educational process has become more complex each day, because the children arrive in schools with many conflicts - which they could not solve on their own. For this reason, it is important to take a careful and individual look with each child. The objective of this study has been to show how playful meetings in the school playroom help the child to restructure their own history and to develop in a significant way in several aspects. The methodology consisted of a qualitative research whose case study was based on Winnicott's books. The results were the observations - made by the teacher - about the development and advances who Carlos obtained at the end of the meetings. We concluded that the school playroom helped Carlos face and resolve his childhood conflicts through play.
\end{abstract}

Keywords: playroom, aggressiveness, childhood, conflicts and learning. 


\section{INTRODUÇÃO}

Neste artigo produz-se um debate acerca da importância do brincar para a superação de conflitos emocionais na infância. Nesse sentido, o trabalho foi realizado durante um ano e meio com uma criança que nos auxiliou nesta reflexão e a qual recebeu o nome fictício: Carlos.

Carlos é participante do projeto Brinquedoteca Escolar que tem como objetivo trabalhar com crianças que apresentam dificuldades nas interações sociais em sala de aula e contribuir para o desenvolvimento emocional e social. Este aluno foi indicado a participar do projeto por ser considerado uma criança "agressiva" com dificuldades de aceitar regras, pouca comunicação com os colegas e esquiva-se de afeto.

Tendo em conta estas características, realizamos uma entrevista com o responsável da criança e sua professora. E, a partir disso, começamos a realizar nosso trabalho na brinquedoteca escolar, utilizando o brincar espontâneo como atividade central nos encontros com a criança.

No desenrolar do projeto foi possível compreender Carlos, seu entorno, as questões internas que o incomodavam e, observar transformações em suas interações sociais em sala de aula. Carlos, por meio de suas brincadeiras se comunicou conosco e, à medida que o vínculo com ele foi sendo construído, pudemos apoiá-lo na reconstrução de sua história. Pois, conforme Aberastury

[...] a criança expressa seus conflitos e, deste modo, podemos reconstruir seu passado, assim como no adulto fazemo-lo através das palavras. Esta é uma forma convincente de que o brinquedo é uma das formas de expressar os conflitos passados e presentes (p. 17, 1992).

O objetivo deste trabalho é mostrar a importância que a brinquedoteca possui dentro da escola e o quanto os encontros lúdicos/o brincar ajudam a criança a reestruturar sua própria história e a se desenvolver de forma significativa em diversos aspectos .

\section{METODOLOGIA}

Este projeto foi realizado de abril de 2015 a dezembro de 2016, com a supervisão e orientação da Profa Dra Andréia Cristiane da Silva Wiezzel. O qual é uma pesquisa qualitativa de estudo de caso, cujo projeto foi aprovado pelo Comitê FCT - Unesp (Processo no 045860/2014).

O trabalho começou com o contato com a direção da escola, na qual fomos recebidos pela equipe gestora para apresentarmos e esclarecermos o nosso projeto. Após esta etapa, foi marcada uma reunião com as professoras da creche para extrair todas as dúvidas. Feito isto, deu-se início à seleção das crianças que participariam da pesquisa.

Decidido os participantes, um encontro foi proposto com os pais ou responsáveis, para a devida autorização de participação e uma entrevista com coleta de dados que possivelmente poderia nos auxiliar nas estratégias de trabalho com a criança.

Em seguida, todas as informações coletadas foram analisadas pela professora que procurou adequar cada criança com o perfil de cada estagiária. Nesse sentido, toda a equipe foi preparada com base em Winnicott, sendo dois livros - "A CRIANÇA E O SEU MUNDO" e "PRIVAÇÃO E DELINQUÊNCIA" - as principais obras para orientação e fundamentação da pesquisa.

Contudo, Carlos foi selecionado para o Projeto Brinquedoteca Escolar. Visto que ao final do período (estabelecido) de encontros com a criança, foi realizada uma entrevista com a professora para observarmos e analisarmos todo o desenvolvimento e avanços do garoto.

\section{RESULTADOS}

A professora foi entrevistada ao final da pesquisa e nos forneceu os seguintes dados: "ele tem melhorado muito, está com bom humor, está mais tranquilo do que agitado, porém ainda empurra os amigos. 
Todavia a professora afirmou que sua solidariedade "melhorou" e sua aprendizagem também, e acredita que hoje, Carlos, está mais feliz. Visto que, em relação à pesquisa relatou que: "o que posso perceber é que os encontros têm feito muito bem para o aluno, espero que para o ano que vem ele possa participar desse tipo de projeto novamente".

\section{DISCUSSÃO}

\section{PARTICIPANTE}

Carlos foi fruto de uma gravidez indesejada, no momento em que sua mãe tinha dois filhos (um menino e uma menina) pequenos. Não há nenhuma informação do irmão mais velho, somente da irmã - a qual Carlos convive e possui afetividade. Visto que quando Carlos, completou 3 anos, sua mãe o abandonou. Porém, seu avô materno, não permitiu que ele fosse para a adoção e assim, assumiu sua guarda.

Durante a entrevista, o avô de Carlos, declara ter um bom relacionamento afetuoso com o neto. No entanto, isso não ocorre com a avó (não biológica), pois a mesma é brava e o põe de castigo no quarto com a irmã.

Contudo, esta entrevista encontra-se pautada na afirmação de Winnicott:

Para que os bebês se convertam, finalmente, em adultos saudáveis, em indivíduos independentes, mas socialmente preocupados, dependem totalmente de que lhe seja dado um bom princípio, o qual está assegurado, na natureza, pela existência de um vinculo entre mãe e o seu bebê (p.17, 2015).

Dessa forma, em conversa com a professora esta justificou a indicação de Carlos ao projeto devido ao fato do garoto a desafiar constantemente, por não aceitar regras, não saber mais como lidar com a sua indisciplina, por alguns momentos de agressividade e pela dificuldade em receber carinho. Sendo assim, Carlos ingressou no projeto quando tinha 5 anos e 6 meses.

\section{OBSERVAÇÃO}

Foram realizadas duas observações na sala de aula no período da manhã. Sem ser apresentada à turma fiquei por perto só analisando sem deixar transparecer que estava ali para acompanhar Carlos.

$\mathrm{Na}$ primeira observação, a turma estava jogando bola e a professora fez algumas orientações, sendo uma delas que: deveriam ter cuidado para não jogar a bola no vizinho ao lado (muro baixo). Desde o início Carlos tentou propositalmente jogar a bola no vizinho - o que deixou claro, a afirmação de que ele não aceita regras (característica mencionada por sua professora).

Muitas foram as tentativas da professora lembrando as crianças para que jogassem a bola para a frente e não para o lado, até que a façanha fora conquistada: a bola havia sido lançada no vizinho com um chutão de Carlos. Foi nítido ver a satisfação em seus olhos de ter desobedecido a uma ordem, porém, depois que a professora chamou a sua atenção, Carlos se propôs a buscar a bola. Mas, a professora não permitiu, pois ele teria que pular o muro.

Já na segunda observação, juntei-me ao grupo em uma brincadeira (pato e ganso) na qual interagi com a maioria das crianças e, infelizmente, com Carlos não foi possível, pois ele se manteve à distância (outra característica mencionada por sua professora). Visto que, na volta para a sala de aula, Carlos estava de cabeça baixa, muito quieto e, quando a professora o questionou, ele a respondeu de uma forma grosseira e curta. Em seguida, fomos ao refeitório e Carlos, estando nessa situação, não comeu quase nada. 


\section{ENCONTROS LÚDICOS}

Na primeira vez em que convidei Carlos para brincar, ele foi sem contestar, mas não foi de mãos dadas comigo. Já na sala da brinquedoteca, brincou com potinhos coloridos de tamanhos diferentes onde fez várias combinações, porém ele não conseguia encaixar, pois forçava o encaixe (de forma desorganizada).

Depois passou a olhar a casa de madeira. Decidiu então, pegar todos os móveis de brinquedos e colocando-os amontoados, no andar de cima da casinha. Essas brincadeiras, sobretudo com a casa, mostraram possibilidades de problemas diários de Carlos e a dificuldade do garoto em resolvê-las.

Cansado de tentar organizar a casa (sem sucesso), passou a montar um quebra cabeça - o qual o deixou entediado. Após a montagem de algumas peças, Carlos começou a brincar novamente com a casinha, visto que em momento algum, conseguiu deixar a casa com aspecto de lar, embora se esforçasse.

Nos encontros posteriores a casa era sua principal brincadeira, onde todos os móveis ficavam no andar de cima e, até os carros foram parar no teto. Diante disso, perguntei a ele se a casa era pequena e se morava muitas pessoas. Ele não respondeu às perguntas, só disse "fico da hora que chego, até o outro dia no quarto".

A angústia é sempre um fator na brincadeira infantil e, frequentemente, um fator dominante. A ameaça de um excesso de angustia conduz à brincadeira compulsiva, ou à brincadeira repetida, ou a uma busca exagerada dos prazeres que pertencem à brincadeira (WINNICOTT, 2012, p. 162).

Desse modo, começamos a estabelecer um vínculo devido aos encontros e um ato durante a brincadeira que Carlos preparou uma bebida e serviu para mim nas xícaras que ele havia colocado na parte de cima da casinha de madeira.

Contudo, no ultimo encontro lúdico do ano levei um presente para ele - o qual gostou muito. Porém, alguns minutos depois, se entristeceu e disse "você não vai voltar mais, né?!". De forma tranquila, respondi que assim que terminassem as férias, estaria na escola novamente.

No dia do retorno às aulas fui até a escola para fazer a acolhida. Nesse dia, os professores e equipe gestora proporcionaram um dia de brincadeiras e, Carlos, ficou feliz em me ver, até me abraçou, todavia percebi um olhar triste.

No primeiro encontro de volta às aulas, Carlos se mostrou agressivo, batia em todos os brinquedos com o martelo. Segundo Winnicott (2015, p. 161) "dão escoamento ao ódio e à agressão nas brincadeiras, como se a agressão fosse alguma substância má de que fosse possível uma pessoa livrar-se".

Durante um determinado período, Carlos ficou meses sem comparecer à escola. Quando retornou ao projeto, a casa de madeira foi seu primeiro brinquedo e, assim, pegou as ferramentas para consertar a casa e os carros. Isto deixava claro que tentava reorganizar os móveis no andar de cima, os quais estavam amontoados. E, algum tempo depois, foi arrumando/organizando tudo, colocou até as flores na janela da casinha.

Então, Carlos, disse "estou com a minha mãe, minha irmã e o tio". "Você está feliz?" indaguei. "Tô feliz, tô com a minha mãe e com a minha irmã" - respondeu. Durante algum tempo foi arrumando tudo até colocou flores na janela.

Tudo estava se resolvendo, suas brincadeiras evoluíam. Mas, infelizmente, ocorreu um novo período de faltas, e quando Carlos retornou, estava arredio, muito nervoso e de forma alguma queria brincar comigo.

Acredito que no período de faltas ( 6 semanas) somado às férias, ele imaginou que tivesse sido abandonado por mim. Além disso, a diretora relatou que ele havia sido expostos à cenas de 
grande violência, onde viu a mãe ser presa. Visto que, em meio a tantos acontecimentos, ficou desaparecido por alguns dias.

Ser capaz de tolerar tudo o que podemos encontrar em nossa realidade interior é uma das grandes dificuldades humanas, e um dos importantes objetos humanos consiste em estabelecer relações harmoniosas entre as realidades pessoais internas e as realidades externas.

Sem tentar nos aprofundar muito na origem das forças que lutam pelo predomínio dentro da personalidade, posso assinalar que, quando as forças cruéis ou destrutivas ameaçam dominar as forças de amor, o individuo tem de fazer alguma coisa para salvar-se, e uma das coisas que ele faz é por para fora o seu íntimo (WINNICOTT, 2012, p. 98-99).

Diante disso, teria que estabelecer novamente o vínculo de confiança com Carlos. Pois ele estava muito agressivo, não conversava e nem pegava em minha mão. Cuidadosamente me fiz presente e resistente às suas manifestações de raiva. De modo que, grandes dificuldades também foram encontradas pela professora. E, conforme Winnicott "a agressividade, que dificulta o trabalho da professora, é quase sempre dramatização da realidade interior que é ruim demais para ser tolerada como tal" (2012, p. 99).

Com isso, Carlos voltou a falar comigo para reclamar de uma atividade de jardinagem, onde alguém havia colhido seu pé de alface. Daí em diante reestabeleceram-se os encontros lúdicos e, novamente, voltou a brincar com os brinquedos de encaixe com o objetivo de encaixá-los de qualquer forma.

Irritando-se com facilidade, já com quebra cabeça desistiu de montá-lo na metade e, pela primeira vez me pediu para ler um livro para ele chamado "Quem é a mãe do filhote", cuja história havia muitos filhotes e algumas dicas para adivinhar a mãe correspondente. Neste momento, Carlos disse "tô com saudade da minha mãe e irmã, meu vô vai arranjar dinheiro para buscar ela".

A partir deste encontro, Carlos passou a brincar com jogos de encaixe e boliche (o qual batia com muita força com o próprio pino no pino) e, na medida em que ia brincando, conversava e jogava de forma mais calma. De modo que, nesta etapa, nas vezes que brincou com a casinha de madeira, foi somente para consertar e organizar alguns móveis que foram para a parte de baixo, como por exemplo: a mesa, a geladeira e enfim o carro saiu do teto e foi para a garagem.

Em nosso ultimo encontro, já no final do ano letivo de 2016, Carlos estava sorridente, brincamos um pouco, porém ele queria me levar para conhecer a mostra pedagógica da escola, na qual ele tinha vários trabalhos expostos. Sendo assim, passeamos por todas as sessões, cada uma tinha um tema e ele me contava como e por que fizeram. Ao observar os trabalhos de Carlos, foi nítida constatar a sua evolução nas atividades.

\section{CONCLUSÃO}

Conclui-se que este projeto nos permitiu entrar no universo infantil e ajudar Carlos a resolver seus conflitos através da brincadeira. O garoto na vida real não podia bagunçar ou organizar a sua casa. No entanto, brincando, ele pôde deixar fluir toda sua energia, reelaborando problemas e soluções, além do fato que passou a ter uma pessoa exclusiva para escutá-lo, apoiálo, aceitá-lo e demonstrar sua importância como pessoa.

É possível observar que, à medida em que a brincadeira evoluía, Carlos também passava pela mesma situação. Sendo assim, o trabalho é longo e delicado, já que a agressividade vem crescendo no ambiente escolar, pois o que é de inteira responsabilidade da família está sendo deixado a cargo da escola. 
Portanto, a brinquedoteca pode ser um grande aliado deste trabalho. Pois os conflitos que as crianças vivem, estão se tornando cada dia mais frequentes e maiores. Desse modo, toda a ajuda no processo de educação deve ser bem vinda.

\section{REFERÊNCIAS}

WINNICOTT, D.W. A criança e o seu mundo. 6a ed. Rio de Janeiro: LTC-Livros Técnicos e Científicos Editora S.A., 2015.

WINNICOTT, D.W. Privação e Delinqüência. 5a ed. São Paulo: Editora WMF Martins Fontes LTDA., 2012.

ABERASTURY, A. A criança e seus jogos. Porto Alegre: Artmed, 1992. 